Viso - Cadernos de estética aplicada

Revista eletrônica de estética

ISSN 1981-4062

No 11, jan-jun/2012

http://www.revistaviso.com.br/

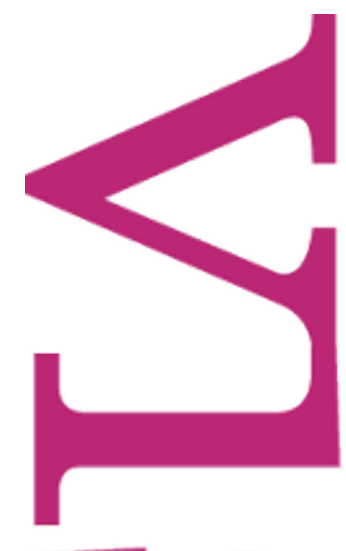

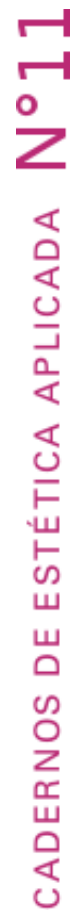
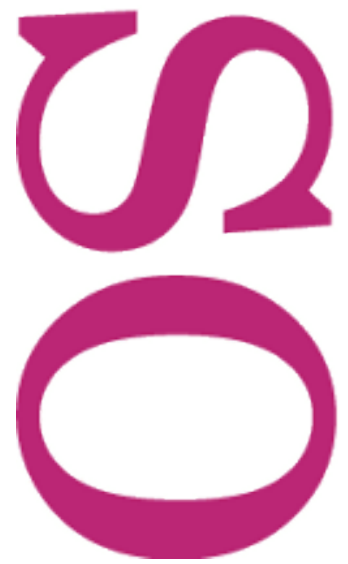

\title{
Questões de origem sobre o gosto
}

Carla Damião

Universidade Federal de Goiás (UFG)

Goiânia, Brasil 


\section{RESUMO}

\section{Questões de origem sobre o gosto}

Este artigo apresenta questões de origem na formação da estética no século XVIII. Essas questões dizem respeito ao gosto ou constituição do juízo estético com base na experiência que reúne a sensibilidade e o intelecto. O "gosto mental", no entanto, parte de uma discussão no âmbito da moral e se relaciona estreitamente com a epistemologia do empirismo nascente. O propósito deste artigo é recuperar elementos dessa discussão para fomentar uma recuperação do sentido de estética como percepção.

Palavras-chave: gosto - percepção - sentidos internos - desinteresse

\section{ABSTRACT}

\section{Questions of Origin about Taste}

This article presents questions of the origin of Aesthetics in the 18th Century. These issues concern the constitution of taste or aesthetic judgment based on the experience that combines sensitivity and intellect. The "mental taste", however, begun to be discussed in the field of morality, and relates closely to the epistemology of early empiricism. The purpose of this article is to recover elements of this discussion in order to foster a recovery of the meaning of aesthetics as perception.

Keywords: taste - perception - inner senses - disinterestedness 
DAMIÃO, C. "Questões de origem sobre o gosto". In: Viso: Cadernos de estética aplicada, v. VI, n. 11 (janjun/2012), pp. 224-235.

\section{DOI: 10.22409/1981-4062/v11i/136}

Aprovado: 31.08.2012. Publicado: 07.09.2012.

(C) 2012 Carla Damião. Esse documento é distribuído nos termos da licença Creative Commons Atribuição-NãoComercial 4.0 Internacional (CC-BY-NC), que permite, exceto para fins comerciais, copiar e redistribuir o material em qualquer formato ou meio, bem como remixá-lo, transformá-lo ou criar a partir dele, desde que seja dado o devido crédito e indicada a licença sob a qual ele foi originalmente publicado.

Licença: http://creativecommons.org/licenses/by-nc/4.0/deed.pt_BR

Accepted: 31.08.2012. Published: 07.09.2012.

(C) 2012 Carla Damião. This document is distributed under the terms of a Creative Commons Attribution-NonCommercial 4.0 International license (CC-BY-NC) which allows, except for commercial purposes, to copy and redistribute the material in any medium or format and to remix, transform, and build upon the material, provided the original work is properly cited and states its license.

License: http://creativecommons.org/licenses/by-nc/4.0/ 


\section{Introdução}

O sugestivo título da conferência de Barry Smith anunciada para o XV Encontro da ANPOF, "The Sensory and the Multisensory: Hearing with our eyes, tasting with our ears" ("O sensorial e o multisensorial: ouvindo com nossos olhos, experimentando com nossos ouvidos"), é tão interessante quanto os comentários do músico brasileiro Hermeto Paschoal sobre nossa capacidade de ver e ouvir, na entrevista presente no filme intitulado Janela da alma (dirigido por João Jardim e Walter Carvalho, 2001). Hermeto Paschoal mostra a nuca como espécie de órgão sensorial receptor real da música, negando ao ouvido a função principal de apreensão do som; o mesmo para os olhos, que não seriam os órgãos detentores da capacidade da visão, sendo esta apreendida por uma espécie de olho interno, localizado entre os dois olhos na altura das sobrancelhas. Talvez não exista aqui uma função multisensorial, mas a identificação de sensações e apreensões que ocorrem por meio de um sentir sensorial internalizado acima de tudo. Trata-se, sobretudo, da capacidade perceptiva que busca reunir a experiência individual subjetiva com o objeto que se the apresenta. Pode-se identificar esta capacidade perceptiva como o elemento ativo capaz de ajuizar sobre o objeto, cuja liberdade de julgamento não caracteriza os sentidos externos por serem estes reativos aos objetos que os afetam. Desta forma, a percepção requerida não se encontra na esfera da necessidade e do interesse. Resumem-se aqui três das ideias fundadoras da composição do juízo estético: percepção, gosto e a categoria estética e moral do desinteresse. Percepção e gosto formam o que se passou a reconhecer como "estética do espectador"1, cujo fundamento filosófico diz respeito não apenas à constituição da subjetividade moderna e às questões epistemológicas a ela relacionadas, mas remetem igualmente ao contexto social e histórico da formação de um público de espectadores ${ }^{2}$ nos séculos XVII e XVIII nos grandes centros urbanos europeus. Teremos em vista, neste artigo, um destes contextos, o britânico, pré-kantiano, cujo maior pólo de interesse é o de nos mostrar como, no nascimento da estética moderna, esta não se separa seja do terreno lógico e epistemológico, seja da filosofia moral, por meio de teorias da percepção e da invenção da ideia de sentidos internos, como o senso moral em Shaftesbury e o senso de beleza em Hutcheson.

O desenvolvimento deste artigo será feito, em um primeiro momento, com base na teoria de Shaftesbury; e, posteriormente, na teoria de Hutcheson, de forma a conferir elementos para a associação e diferenciação das teorias destes autores, tendo em vista a associação entre sentido moral e sentido de beleza.

\section{Shaftesbury}

Atribui-se ao terceiro Conde de Shaftesbury, Anthony Ashley Cooper, educado por Locke e influenciado pelos estóicos e o neoplatonismo de Cambridge, a teoria que se contrapõe ao deísmo, conhecida como sentimento moral [moral sense], bem como a ideia de desinteresse que teria se tornado o principal fundamento da Estética Moderna. Importa 
notar a repetição da equação socrática-platônica entre o belo e o bom ${ }^{3}$ reunida à ideia de sentido interno [internal sense]. Este é o conceito central que marca a influência de Locke sobre Shaftesbury, para quem não se pode negar que há um sentido natural de belo nas coisas, que torna esse sentido interno uma resposta imediata do que se apresenta no objeto como qualidade. Ele desdobra esse sentido em dois tipos: 1. O que se refere à beleza interior [inward beauty] possuindo uma relação de identidade com o bem moral, e 2. A beleza exterior [outward beauty] que se relaciona com o bem moral por meio da expressão. Laurent Jaffro 4 chama a primeira de "beleza da moralidade" e a segunda de "moralidade da beleza".

A associação entre beleza e moralidade que se desdobra tem por base a distinção entre o que é meramente sensível e o que é sensível e reflexivo, constituindo assim a ideia de um "mero sentido" e um sentido que é reflexivo. Essa distinção auxilia Shaftesbury a estabelecer a objetividade e universalidade da virtude e da beleza, isto é, um sentido que é quase uma capacidade ou faculdade universal e natural nas pessoas. Esse conteúdo cognitivo forma internamente o princípio que comandará o gosto.

Apesar de tais conclusões, Shaftesbury não pode ser entendido como um idealista ou racionalista, posto que sua teoria supõe testar as ideias no concreto e indicar um juízo empírico específico, visto que os sentidos podem enganar-se ao voltarem-se para objetos errados. Mesmo assim, há quem considere, em retrospectiva, sua teoria como "irrealista" ${ }^{5}$, mesmo que se note um esforço especulativo, concepção de métodos que abrangem o social e o político, por exemplo, na busca pelo aprimoramento do gosto. "Treinar o gosto" não significa cultivar preferências meramente subjetivas, porque este está fundamentado em propriedades cujos critérios são reais e objetivos, bastando que o conteúdo destes se manifeste ao sentimento. Este termo é quase um correlato de juízo e não de emoção. O sentimento se distingue da emoção e do que caracterizaria o sentimentalismo e deve, ao guiar o gosto, separá-lo da imaginação.

Para Shaftesbury a tarefa da filosofia é a de "nos ensinar, manter-nos as mesmas pessoas individuais e, assim, regular a direção de nossa imaginação, de nossas paixões e humores, a fim de nos tornar compreensíveis a nós mesmos e cognoscíveis a outros". ${ }^{6}$ Neste pressuposto o desenvolvimento do gosto é um dos elementos da educação moral.

Preocupado com o auto-engano, Shaftesbury enumera em "Plastics" as razões pelas quais o gosto de um gentleman pode ser sujeito ao engano. Se tratar-se de um gosto apenas prático e empírico, será falso por tornar-se "interessado", tornando-se parte de seu próprio juízo ao defender um estilo particular. Mesmo que o gosto seja, em relação ao belo, caracterizado por sua imediaticidade, pode ser facilmente enganado.

Torna-se evidente, portanto, como é também em outras teorias do gosto, que o gosto se forma necessariamente como juízo. O gosto pode ser educado e corrigido, por isso "o grande negócio nisto, é corrigir o gosto". ${ }^{7}$ 
A faculdade "inimiga" do gosto é a imaginação [fancy]. De acordo com Shaftesbury ela é a causa da perda da razão e da loucura, visível na imposição que se quer fazer sobre os demais. Um gosto descontrolado é sujeito à loucura. O gosto, portanto, deve ser controlado por meio de "um domínio interno sob o exercício externo do gosto". ${ }^{8}$

Se o gosto é um resultado a ser estabelecido, ele não é relativo a uma experiência estética com o meramente sensorial, mas ele é fruto do juízo e não o ponto de partida para a construção deste. Esta afirmação torna a teoria de Shaftesbury bastante dissonante das outras teorias gosto do final do século XVIII que o sucederam, posto que o gosto se afirma como um juízo em concomitância com a experiência, sem ser decorrente ou posterior a este. O gosto é ao mesmo tempo mental e imediatamente prazeroso e se assim o for, não se pode falar em gosto errado. O que pode se constituir como erro é a sobreposição da imaginação e do interesse sobre o sentido interno moral.

O sentido interno, portanto, correspondente ao "eu verdadeiro", jamais é corrompido, mas o gosto, na condição de uma manifestação externa, pode ser facilmente corrompido. O controle moral interno é determinante para que o gosto seja julgado bom ou mau.

Qual é a relação entre sentido moral e desinteresse? Em primeiro lugar, é preciso entender que "interesse" não é exatamente uma espécie de egoísmo, conceito rebatido por Shaftesbury ao se posicionar contra Hobbes, pois o interesse público é benéfico. No entanto, o interesse não deve guiar exclusivamente a ação. $O$ interesse que se critica é o interesse particular e a este se opõe o "desinteresse" como um desprendimento selfless - e legítimo investigador da verdade. Este é o sentido que se aproxima do senso moral e estético, ambos irremediavelmente inseparáveis em Shaftesbury.

Se o interesse for particular e egoísta, a proximidade com as paixões submete-o a problemas morais. Além do fato de que, uma vez aliado à paixão, o interesse é diretamente associado ao que me agrada ou desagrada de uma forma, inclusive, passageira, algo que me agrada hoje pode vir a desagradar amanhã. Podemos pensar que, com estes argumentos, Shaftesbury indicaria o caminho da "paixão calma" e da "atitude desinteressada". Para Townsend, este não é o caso e é por isto que sua análise é tão interessante e de muita valia para a distinção com a noção de desinteresse em Kant e da atitude desinteressada no romantismo.

Em sua perspectiva, é preciso separar o interesse do prazer, visto que, se ocorre uma identidade entre os dois, isso pode conduzir à relatividade e à contradição do ora isto ser prazeroso, ora não, ora isto interessa, ora não. Esta conclusão, transposta para os valores estéticos e morais, redundaria em afirmar que ora algo é belo, ora é feio; ora é bom, ora é mau. A aproximação de interesse e prazer diz respeito ao interesse individual, mas há, como dissemos, o interesse público que não é negativo; e, além do interesse público e privado, há o verdadeiro desinteresse. Todos os três são referidos à natureza e ao belo - ambos relacionados a uma ordem na qual o eu se descobre. 
Pelo exposto, podemos entender que não há, em geral, uma separação entre estética e moral, ou do contrário poderíamos concluir que se o interesse é uma categoria pertencente à moral, a estética deveria ser igualmente interessada. Há diferenças que reforçam o aspecto moral, como sentido interno que comporta a verdade da natureza e rege as manifestações externas do gosto e da expressão da beleza.

\title{
Francis Hutcheson
}

Não se coloca em dúvida a defesa que Hutcheson faz de Shaftesbury contra Hobbes e Mandeville, e a adoção do senso moral [moral sense] para a construção, por analogia, do sentido de belo [sense of beauty]. Faz-se necessário, no entanto, mostrar as diferenças que nos conduzirão à epistemologia de Locke para pensarmos como estes sentidos se constituem. Ressalve-se que não existe exatamente uma estética em Locke ${ }^{9}$, mas a adoção de sua epistemologia será a diferença que encontraremos na teoria de Hutcheson e que corresponderá a um dos fundamentos de sua diferença com a teoria de Shaftesbury. Tendo em vista que a ideia de sentido de belo remete à de senso moral de Shaftesbury, segundo nos diz o próprio Hutcheson no prefácio ao Inquiry into the original o four ideas of beauty and virtue:

\begin{abstract}
Este sentido moral de beleza em ações e afetos pode parecer estranho à primeira vista.Alguns dos nossos moralistas se sentem ofendidos com meu Lord Shaftesbury, tão acostumados que estão a deduzir cada aprovação, ou aversão, a partir de pontos de vista racionais de interesse (a não ser unicamente por ideias simples dos sentidos externos) [...] este senso moral [também] não tem relação com ideias inatas, como aparecerá no segundo tratado.Nossos senhores de bom gosto podem nos falar sobre um grande número de sentidos, gostos, e apreciação da beleza, harmonia, imitação na pintura e poesia.E não podemos nós encontrar também na humanidade o gosto da beleza no caráter, nas maneiras? ${ }^{10}$
\end{abstract}

Essa citação, além de mostrar a filiação com Shaftesbury, apresenta o contexto no qual se discute o gosto reunido a questões epistemológicas, o que fica evidenciado na separação do senso moral e as ideias inatas, bem como em procurar na natureza humana o "gosto da beleza no caráter e nas maneiras". Porém, a afirmação do caráter universal da humanidade torna-se uma preocupação pertinente, o que podemos observar no seguinte parágrafo que escreveu na apresentação de seu próprio tratado:

No primeiro tratado, o autor, talvez, tenha ido, em alguns casos, longe demais ao supor uma maior concordância da humanidade em seu sentido de beleza do que a experiência pode confirmar, mas, sobretudo, o que ele se empenha em mostrar é "que há algum sentido de beleza naturalnos homens; que encontramos tanto um grande acordo dos homens em sua apreciação de formas, quanto em seus sentidos externos, os quais todos concordam ser natural; e que o prazer ou a dor, o deleite ou aversão, são naturalmente unidos a suas percepções". ${ }^{11}$

Percebe-se claramente nesta citação a analogia deste sentido de beleza com os sentidos externos, cujo fundamento se busca na natureza humana. Esse sentido do belo, 
segundo Emily Michael em seu artigo intitulado "Francis Hutcheson on aesthetic perception and aesthetic pleasure", não pode, contudo, ser identificado ao sentimento de prazer. A autora argumenta que Hutcheson fala da experiência do belo como "acompanhada" ou "reunida" ao prazer. O prazer só poderia, neste sentido, surgir em conjunção com a ideia de belo ou como resultado dessa ideia. A associação do belo ao prazer ou/e emoção era comum neste período e permaneceu posteriormente, por exemplo, em Thomas Reid, mas há um pressuposto importante nesta discussão que difere Hutcheson dos demais: sua teoria da percepção.

Artigo 8.0 único prazer sensível que alguns de nossos filósofos parecem considerar é aquele vinculado às ideias simples de sensação.Mas há prazeres muito maiores nas ideias complexas de objetos ditos harmoniosos, belos ou regulares.Ninguém poderia negar que um lindo rosto ou um quadro excelente são mais deleitosos do que uma cor qualquer, por mais forte e viva que seja, ou que se sinta mais prazer ao ver o sol erguerse entre as nuvens, colorindosuas bordas como um halo luminoso, ou ao contemplar uma bela paisagem ou um edifício regular, do que à vista do céu azul claro, do mar sereno ou uma vasta planície deserta, sem bosques, montanhas, rios ou edificações. Estes últimos não são tão simples quanto parecem. Igualmente na música, o prazer de uma bela composição é incomparavelmente maior que o de uma nota isolada, por mais doce, plena e ressonante que seja. ${ }^{12}$

A teoria da percepção de Hutcheson, construída no corpo da teoria empirista escocesa, é a base para compreensão dos sentidos internos. Em seu Compêndio de Lógica [Logicae compendium], Hutcheson distingue três tipos de ideias: de 1 . sensação, de 2 . imaginação e de 3. pura intelecção. O que se entende aqui por ideia são ideias que têm sua origem na sensação, e podem ser externas ou internas. 1. Uma ideia de sensação é entendida como uma percepção passiva e imediata da sensação externa ou interna; 2. Uma ideia de imaginação é uma impressão corpórea que surge na mente, sem utilizar os órgãos corporais. A imaginação reúne ideias fracas de coisas que foram percebidas antes pela sensação; 3 . Ideias de pura intelecção são ideias sem imagens ou ideias gerais, adequadas por reflexão e comparação abstrata. Neste contexto, a ideia de beleza é uma ideia de sensação interna que pode se tornar uma ideia complexa. Neste sentido, em seu Essay on the Nature and Conduct of the Passions and Affections, ao explicar percepção e sentidos, ele nos diz:

(1) as percepções que são puramente sensíveis, recebidas pelos próprios sentidos são: paladar, olfato, cores, sons, frio, calor, etc;

(2) as ideias concomitantes universais, que devem servir a qualquer ideia, são: duração e número. As ideias que acompanham as mais diferentes sensações são: extensão, figura, movimento, repouso;

(3) De todas essas [ideias] nós devemos distinguir 'os prazeres percebidos sobre a recepção prévia e a comparação das várias percepções sensíveis, com suas ideias ou ideias intelectuais, quando nós encontramos uniformidade, ou semelhança entre elas'. Essas [ideias] são consideradas pelas percepções do sentido interno. ${ }^{13}$ 
Segundo o desdobramento deste raciocínio: "Ideias concomitantes, ou ideias de qualidades primárias, são, portanto, ideias intelectuais que acompanham percepções sensíveis de diferentes sentidos. As ideias concomitantes universais de duração e número são ideias intelectuais que acompanham ideias de nossas sensações interna e externa". ${ }^{14}$ A diferença entre estas reside nas ideias de qualidades primárias e secundárias: "Todas surgem sem nenhuma ideia que as reúna ou as compare". ${ }^{15}$ Ao considerarmos a ideia de beleza, portanto, nós só percebemos o prazer estético em reunião com a uniformidade das ideias sensíveis acompanhadas pelas ideias intelectuais ou concomitantes. A diferença está na sensação direta e na sensação reflexiva.

O caminho que configura a ideia de belo, segundo a interpretação de Michael, é que certas propriedades relacionais da figura e do movimento excitam na mente uma ideia relativa a 'algumas proporções de figura com cor' ou 'algumas proporções de tempo', bem como de tons e notas. Essa ideia, por sua vez, excita na mente a ideia de belo.

A apreensão dos objetos nos quais existe uniformidade em meio à variedade, portanto, ocorre como sensação agradável. Nós só temos a ideia de beleza após experimentar esta sensação, sem, contudo, conhecer sua causa. Segundo comenta Jaffro: "A qualidade é a causa da experiência da beleza sem ser o conteúdo ou a significação dessa experiência". ${ }^{16}$ Por isso, a beleza é uma propriedade relacional, posto que a qualidade que gera o prazer não vem acompanhada da consciência desta. Há percepção do prazer que é proporcionada pela experiência com a uniformidade em meio à variedade. A ideia simples é uniforme, não divisível em partes, enquanto a percepção que envolve ideias sensíveis com suas ideias concomitantes é sempre complexa.

Michael comenta que

Alexander Gerard, outro esteta do lluminismo escocês, argumenta que a qualidade sensível da beleza 'é complexa em seus princípios, mas perfeitamente simples em seus sentimentos. Se isto puder parecer uma contradição, lembremos que dois licores de diferentes sabores podem, em sua mistura, produzir um terceiro sabor, o qual deve excitar no paladar uma sensação tão simples quanto a que recebeu dos outros ingredientes. Semelhantemente, a percepção da brancura é tão simples quanto a de qualquer cor; mas os filósofos sabem que, [...] ela é composta pelas sete cores primárias".$^{17}$

É fundamental notar o papel que o desinteresse assume também em relação à moral. $\mathrm{O}$ prazer desinteressado em Hutcheson está em oposição à visão de que todo prazer é resultado da satisfação de um interesse pessoal. Sua atenção neste caso refere-se a uma preocupação ética, não estética; ele quer mostrar que o prazer que nós experimentamos na percepção da ação virtuosa não é o resultado de nenhuma vantagem pessoal. Sua discussão sobre a beleza serve, em grande parte, para mostrar que nós podemos experimentar um prazer desinteressado. O prazer estético é 
experimentado como uma medida de intensidade de certas características de qualidades sensíveis, não como resultado de aquisição de alguma vantagem.

Por fim, o critério de uniformidade em meio à variedade, que é a causa instigadora do prazer estético, não é válido como vantagem ou utilidade; é válido como um fim em si mesmo, em vista de sua excelência inerente.

Jaffro ${ }^{18}$ observa uma distinção importante entre as seguintes conceituações: 1. "Sentido moral da beleza" [Moral sense of beauty] e 2. "Sentido natural de beleza" [Natural sense of beauty], a fim de demonstrar a não identidade e mesmo independência entre uma definição e a outra. Há afinidade quando se pensa na percepção ou apreciação estética e ética tendo em vista processos psicológicos. Mas não há como equiparar uma qualidade como a da "benevolência" com a qualidade da "uniformidade e variedade", mesmo sabendo que as ideias de uniformidade, ordem e proporção remetem ao bem viver.

\section{Conclusão}

Esta questão encaminha nossa breve conclusão que nos remete à associação e separação entre moral e estética nos autores estudados. Se em Shaftesbury há uma identidade objetiva entre o bom e o belo, em Hutcheson há que se considerar a função da analogia entre os dois sentidos, sendo o sentido de beleza essencialmente subjetivoreflexivo e sensitivo. Este sentido marcado pelo desinteresse, por sua vez, ao contrário de ser reunido ao sentido moral, torna-se uma experiência que contribui para tornar as relações morais igualmente desinteressadas. A teoria de Hutcheson efetiva um desdobramento da ideia de sentido interno de Shaftesbury, sem gerar a identidade do sentido de beleza com o sentido moral, criando uma relação qualitativa e cooperativa entre os dois sentidos internos.

\section{bibliografia complementar}

HUTCHESON, F. An inquiry concerning beauty, order, harmony, design. Introdução e notas de Peter Kivy. The Hague: Martinus Nijhoff, 1973.

"Concerning some powers of perception, distinct from what is generally understood by sensation". In: An inquiry into the original of our ideas of beauty and virtue, livro I, cap. 1, $2^{\mathrm{a}}$ edição. Londres: 1726. Tradução de Alexandre Amaral Rodrigues. In: PIMENTA, P. P. (org.). O iluminismo escocês. São Paulo: Alameda Casa Editorial, 2011.

BROADIE, A. (org.). The Scottish Enlightenment. Cambridge: Cambridge University, 2003.

KAPP, S. Non satis est. Excessos e teorias estéticas no Esclarecimento. Porto Alegre: Escritos, 2004.

KIVY, P. The seventh sense. A study of Francis Hutcheson's Aesthetics and its influence in the Eighteenth-Century Britain. New York: Burt Franklin and Co, 1976.

"The perception of beauty in Hutcheson's first Inquiry: a response to James Shelley". In: British Journal of Aesthetics, v. 47, n. 43 (October, 2007), pp. 416-431. 
KIVY, P. (org). Estética. Fundamentos e questões de filosofia da arte. Tradução de Euclides L. Calloni. São Paulo: Paulus, 2008.

PIMENTA, P. P. G. A linguagem das formas. Natureza e arte em Shaftesbury. São Paulo: Alameda Casa Editorial, 2007.

TAYLOR, C. As fontes do self. A construção da identidade moderna. Tradução de Adail U. Sobral e Dinah A. Azevedo. São Paulo: Loyola, 1989.

TOWNSEND, D. "Hutcheson and complex ideas: a reply to Peter Kivy". In: Journal of Aesthetics and art criticism, v. 51, 1 (Winter, 1993), pp.72-74.

"Thomas Reid and the theory of taste". In: Journal of Aesthetics and art criticism, v. 61, 4 (Fall, 2003), pp.341-351.

"Lockean aesthetics". In: Journal of Aesthetics and art criticism, v. 49, 4 (Fall, 1991),

pp.349-361.

\footnotetext{
* Carla Damião é professora adjunta do Departamento de Filosofia da UFG.

${ }^{1}$ Cf. o artigo de Cláudio Oliveira presente neste mesmo número da Viso: "Da estética ao terrorismo: Agamben, leitor de Nietzsche e Heidegger", que comporta uma discussão sobre a referência de Agamben à crítica de Nietzsche sobre a estética do espectador remetida à teoria kantiana. Um dos capítulos do livro analisado neste artigo - O homem sem conteúdo - empreende uma "arqueologia do gosto" no contexto francês, passando pela interpretação do Sobrinho de Rameau de Diderot que Hegel faz em sua obra A fenomenologia do espírito.
}

${ }^{2}$ Cf. KELLY, M. (org.). Verbete "Taste". Encyclopedia for Aesthetics. New York: Oxford University Press, 1998.

${ }^{3}$ No diálogo entre Theocles e Philocles: "So that beauty, Said I, and good with you, Theocles, I perceive, are still one and the same" (SHAFTESBURY, A. A. C. Characteristics Of Men, Manners, Opinions, Times. Edição organizada por Lawrence F. Klein. Cambridge: Cambridge University, 1999, p.79).

${ }^{4}$ JAFFRO,L. "Francis Hutcheson et l'héritage shaftesburien: quelle analogie entre le beau et le bien?,

p.

Disponível

em:<http://halshs.archivesouvertes.fr/docs/00/17/43/17/PDF/Jaffro_Hutcheson_analogie.pdf>.

Acesso em 03/11/2012.

${ }^{5}$ Cf. Ibidem, p. 4.

${ }^{6}$ Apud TOWNSEND, D. "Shaftesbury's Aesthetic theory", p. 206. In: Journal of Aesthetics and Art Criticism, v. 41, 2 (Winter, 1982), pp.205-213.

7 Ibidem, p. 207.

${ }^{8}$ Ibidem.

${ }^{9}$ Dabney Townsend comenta a indiferença de Locke à questão da beleza ou das artes, mas diz ser impossível não notar a contribuição de sua epistemologia para o surgimento da Estética, tanto em Shaftesbury, seu aluno, quanto em Hutcheson. Cf. "Lockean Aesthetics". In: The Journal of Aesthetics and Art Criticism, v. 49, 4 (Fall, 1991), p. 349.

${ }^{10}$ HUTCHESON, F. An Inquiry into the Original of Our Ideas of Beauty and Virtue. Cambridge: Cambridge University Press, 2003, Preface, §7. 
${ }^{11}$ Ibidem, Preface, §8.

12 Ibidem, p. 152.

${ }^{13}$ Apud MICHAEL, E. "Francis Hutcheson on aesthetic perception and aesthetic pleasure", p. 243. In: British Journal of Aesthetics, v. 24, n. 3 (Summer, 1984), pp. 241-254.

${ }^{14}$ Ibidem, pp. 245-246.

${ }^{15}$ Ibidem, p. 246.

${ }^{16}$ JAFFRO, L. "As várias maneiras filosóficas de recorrer ao senso comum nas Luzes britânicas". In: Discurso, n. 33, 2003, pp. 35-74.

${ }^{17}$ Alexander Gerard, Essay on Taste, 1759, pp. 163-164. Apud MICHAEL, E. Op. cit., p. 251.

18 JAFFRO, L. "Francis Hutcheson et l'héritage shaftesburien: quelle analogie entre le beau et le bien?". Op. cit., p. 9. 